\title{
PENGARUH ISLAM DAN KEBUDAYAAN MELAYU TERHADAP KESENIAN MADIHIN MASYARAKAT BANJAR
}

\author{
Atqo Akmal \\ Universitas Sebelas Maret Surakarta \\ atqoakmal@gmail.com
}

Diterima 06 Juni 2018 | Direview 09Agustus 2018| Diterbitkan 01 Oktober 2018

\begin{abstract}
:
Banjaresse Culture is a transformation and transculturation of the pre-Islamic religious beliefs with post-Islamization. The contact between the two cultures resulted in a new Banjar entity that strongly influenced by the values of Islam and Malay culture. In art, madibin emerges as the result of assimilation between Malay-Muslim and Banjar art cultures. Madibin has similarities to the oral literature of Malay, pantun and verse, but it is delivered in Banjaresse language, with rhymes that are not necessarily follow certain pattern (eg: must be a-a-a-a or $a-b-a-b)$, no limitation for number of stanza, and not play a particular drama. The emergence of madibin is a transformation of qasida form which present to mark the presence of Islam in the archiplego. The use of tarbang as a musical instrument in madibin, similar to qasida with its rebana-drums. However, madibin is different from the qasida arts whose lyrics are the verses of the song. Madibin is likely an oral literature that has no pattern of regular rbyme and lyric, and not too concerned with the suitability of the lyrics, verse with the rbythm, as an important conformity in the music of qasida.
\end{abstract}

Keywords: Madihin, Oral Literature, Banjarese

\begin{abstract}
:
Budaya masyarakat Banjar merupakan transformasi dan transkulturasi religiusitas kepercayaan pra-Islam dengan paska islamisasi. Pertemuan keduanya menghasilkan suatu entitas Banjar baru yang dipengarubi kuat oleh nilai dan ajaran Islam serta kebudayaan melayu. Dalam bidang kesenian, sastra lisan madibin muncul sebagai hasil dari asimilasi antara kebudayaan Melayu-Islam dan Banjar. Madibin memiliki kesamaan dengan sastra lisan melayu sejenis pantun dan syair, namun disampaikan dalam bahasa Banjar, dengan rima yang tidak mesti teratur (misalnya harus: $a-a-a-a$ atau $a-b-a-b$ ), jumlab bait yang tidak baku, dan tidak melakonkan suatu drama tertentu. Kemunculan madibin merupakan transformasi bentuk qasida yang hadir ke nusantara saat
\end{abstract}




\begin{abstract}
berkembangnya Islam. Penggunaan tarbang sebagai instrumen musik pengiring dalam pertunjukkan madihin, mirip dengan kesenian qasida dengan gendang rebana-nya. Namun madibin berbeda dengan kesenian qasida yang liriknya merupakan bait-bait lagu, madihin merupakan penyampaian sastra lisan sejenis pantun dan syair yang dilagukan, serta tidak terlalu mementingkan kesesuaian bait lirik dengan irama, satu kesesuaian yang penting dalam musik qasida.
\end{abstract}

Kata Kunci: Madibin, Sastra Lisan, Masyarakat Banjar

\title{
Pendahuluan
}

Pada tahun 2014 lalu, kesenian Madibin telah ditetapkan oleh UNESCO sebagai Warisan Budaya Tak Benda milik Indonesia yang berasal dari Kalimantan Selatan. Hal ini menegaskan bahwa kesenian ini merupakan kesenian yang perlu dilestarikan dan dikembangkan. Salah satu caranya adalah melakukan penulisan ini sebagai sebuah bentuk perhatian dan kepedulian terhadap eksistensi kesenian madibin untuk terus dijaga dan melestarikannya sebagai kekayaan khazanah bangsa Indonesia.

Masyarakat Banjar yang secara ekologis mendiami daerah Kalimantan Selatan merupakan salah satu kelompok masyarakat yang mempunyai bentuk sastra lisan baik genre prosa maupun puisi. Sastra lisan di Kalimantan Selatan antara lain pantun, madibin, mantra, baandi-andi, ungkapan, syair balamut, syair dundam, pantun rangkap, lagu mamanda, dan lain-lain. Kewujudan sastera lisan merupakan fenomena budaya yang bersifat universal.

Madibin berasal dari serapan bahasa Arab "madah" yang berarti pujianpujian. Madibin sejenis puisi lama dalam sastra Indonesia, karena ia menyanyikan syair-syair yang berasal dari kalimat akhir yang bersamaan bunyi. Madah bisa juga diartikan sebagai kata-kata pujian, hal ini bisa dilihat dari kalaimat-kalimat dalam bait-bait madibin yang kadang kala berupa pujianpujian. Pendapat lain mengatakan bahwa madibin juga berasal dari bahasa Banjar, yaitu papadah atau mamadahi atau dalam Bahasa Indonesia berarti memberikan nasihat. ${ }^{1}$

Ada yang berpendapat bahawa madihin berasal dari masyarakat kampung Tawia, kecamatan Angkinang, kabupaten Hulu Sungai Selatan

\footnotetext{
1 Mengenai asal muasal penamaan madibin semua budayawan dan peneliti memiliki penjelasan yang sama terkait asal-muasal penamaan madihin, misalnya Rafiek (2012), Pantun Madibin: Kajian Ciri, Struktur Pementasan, Kreativiti Pemadibinan, Pembangunan, dan Pembinaannya di Kalimantan Selatan; dan M. Syukrani, Deskripsi Madibin (Jakarta: Departemen Pendidikan dan Kebudayaan, 1995); dan lain-lain.
} 
Kalimantan Selatan. Dari kampung Tawia inilah madihin kemudian tersebar ke seluruh Kalimantan Selatan, bahkan ke Kalimantan Timur. Pemain madihin yang tersebar di mana-mana pada umumnya berasal dari Kampung Tawia. Salah satu pamadibinan (orang yang membawakan madihin) yang terkenal dari Tawia bernama Dulah Nyanyang.

Madibin berisi humor yang disampaikan dalam bahasa Banjar dengan tujuan untuk menghibur dan memberi nasihat kepada penontonnya. ${ }^{2}$ Seni madibin adalah salah satu kesenian lokal asli di Banjar dalam bentuk sastra lisan. Sastra lisan Banjar diwariskan oleh masyarakat melalui generasi ke generasi. Biasanya madibin disajikan dalam acara-acara keagamaan, pesta pernikahan, acara tradisional, menyambut tamu terhormat (pejabat/tokoh masyarakat), memperingati ulang tahun provinsi, acara nasional dan banyak acara dan agenda lainnya. ${ }^{3}$

Sebelumnya ada beberapa orang peneliti telah menuliskan terkait kesenian Madibin. Misalnya, Saperi Kadir (1992), Maswan Syukrani (1994), A. H. Wardani (1999), Mat Alie Saberi (1977), Muhammad Rafiek (2012), Tajuddin Noer Ganie (2007), Sri Helda Herawati (2013), Kamal Hasuna \& Heppy Lismayanti (2017) masing-masing mejelaskan mengenai Madibin dari struktur kesenian, pementasan, tema, struktur, dan sastra. M. Budi Zakaria (2017) menuliskan Madibin dan relevansinya dengan pendidikan karakter. Siti Faridah, dkk (2017) menuliskan terkait fungsi humor dalam pementasan Madibin sebagai alat protes sosial, media edukasi, media hiburan, dan media memperbaiki moral dan karakter. Selain itu Agus Yulianto (2010) juga telah menuliskannya dalam pendekatan folklore dengan judul "Madibin: Tradisi Tutur dari Zaman ke Zaman".

Indonesia adalah sebuah entitas bangsa dan Negara yang unik. Berdiri di atas perbedaan yang sangat luas, dari keberagaman budaya, agama, bahasa, dialek, kesukuan, marga, dan aspek-aspek humaniora lainnya. Dalam banyak peristiwa dan fenomena sosial, sering terjadi benturan antara kelompokkelompok sosialagama dengan budaya.

Belum ada jurnal atau penelitian yang secara khusus mengkaji kaitan madibin dan pengaruh Islam. Dalam tulisan ini masalah yang dikaji adalah, (1) untuk mengidentifikasi keberadaan pengaruh Islam kepada kesenian tersebut;

2 M. Syukrani, Deskripsi Madihin (Jakarta: Departemen Pendidikan dan Kebudayaan, 1995).

3 S. Faridah, "The Functions of Humor in the Madihin Banjar Art", dalam International Journal of Academic Research and Development Vol. 2 2017, Issue. 4, hlm. 576-581. 
(2) apakah madibin muncul sebagai bentuk akulturasi budaya antara Islam dengan kebudayaan pra-Islam. Lebih dari itu untuk memberikan suatu gambaran tentang Islam di nusantara yang akomodatif terhadap kebudayaan dan kesenian rakyat, berasimilasi dan tumbuh organik dalam memori kolektif masyarakat tersebut.

\section{Metode}

Metode penulisan yang digunakan adalah kualitatif dengan pendekatan deskriptif. Metodologi kualitatif sebagai prosedur penelitian yang menghasilkan data deskriptif berupa kata-kata tertulis atau lisan atau dari bentuk tindakan kebijakan. Penelitian deskriptif bertujuan untuk membuat deskripsi secara sistematis, faktual dan akurat terhadap fakta-fakta, dengan sifat-sifat populasi. Metode deskriptif digunakan untuk mencari unsur-unsur, ciri-ciri, sifat-sifat suatu fenomena dan menginterpretasikannya. ${ }^{4}$

Kata folklore adalah kata serapan dari kata Inggris Folklore, yang berasal dari dua kata yaitu folk dan lore. Folk yang berarti sekelompok orang atau kolektif. Menurut Alan Dundes, folk adalah sekelompok orang yang memiliki ciri-ciri pengenal fisik, sosial, dan kebudayaan sehingga dapat dibedakan dari kelompok-kelompok lainnya. ${ }^{5}$ Lore tidak dijelaskan lebih jauh oleh Dundes. Lore menurut Endraswara (2009) dan Danandja (1984) dimaknai sebagai representasi keinginan folk yang ekspresif. Di dalam folklore terdapat seni, sastra, budaya, dan segala tata kelakuan folk. Semakin tinggi tingkat berpikir folk, berarti folklore mereka juga semakin canggih. Dengan kata lain, folklore dimaknai sebagai kekayaan tradisi, sastra, seni, hukum, perilaku, dan apa saja yang dihasilkan folk secara kolektif. Dengan demikian definisi folklore secara keseluruhannya adalah: sebagian kebudayaan suatu komunitas/kelompok masyarakat yang tersebar dan diwariskan turun-temurun. ${ }^{6}$

Folklor sering dikategorikan sebagai orally (disampaikan secara lisan), bercirikian verbal, berupa kata-kata, tanpa tulisan, milik kolektif rakyat, dan

\footnotetext{
${ }^{4}$ Suryana, Buku Ajar Perkuliahan: Metode Penelitian Kualitatif dan Kuantitatif (Bandung: Universitas Pendidikan Indonesia, 2010).

5 Alan Dundes, The Meaning of Folklore: The Analytical Essays of Alan Dundes (Utah, United States of America: Utah State University Press, 2007).

${ }_{6}$ Penjelasan lebih jauh mengenai lore dipaparkan oleh James Danandjaja, Folklore Indonesia: Ilmu Gosip, Dongeng, dan lain-lain (Jakarta: PT. Pustaka Utama Grafiti, 1984) dan Suwardi Endraswara, Metodologi Penelitian Folklor (Yogyakarta: Media Pressindo, 2009).
} 
memiliki makna fundamental, ditransmisikan dari generasi ke generasi. Namun dalam perkembangan selanjutnya folklore tidak hanya lisan. Ada folklore setengah lisan. Ada pula yang berupa fisik seperti lukisan, rumah, keris, dan sebagainya. ${ }^{7}$

Semua pakar dan peneliti kebudayaan Banjar diantaranya Saperi Kadir (1992), Maswan Syukrani (1994), A. H. Wardani (1999), Mat Alie Saberi (1977), Muhammad Rafiek (2012), Tajuddin Noer Ganie (2007), Siti Faridah (2017) mengkategorikan madibin sebagai bagian dari sastra lisan. Oleh sebab itu pendekatan folklore digunakan agar dalam memahami kesenian madibin tidak parsial dari masyarakat Banjar sebagai pemilik kolektif dari kesenian tersebut.

Pendekatan folklore secara holistik juga digunakan dalam penulisan ini. Pendekatan holistik banyak digunakan oleh para ahli folklore modern. Pendekatan ini memperhatikan kedua aspek yang ada dalam folklor, yaitu folk dan lore-nya. ${ }^{8}$ Dalam penulisan folkloristik, konsep "cermin" masih diterapkan untuk menelaah informasi sejarah dan budaya tentang suatu kelompok, dengan anggapan bahwa itu juga merupakan penanda bagi identitas sosial suatu masyarakat. Folklore sebagai cermin budaya sering mengungkapkan aspek-aspek yang menjadi perhatian khusus. Untuk alasan inilah analisis analisis Folklore dapat memberikan gambaran untuk melihat budaya lain dari 'dalamnya'.' Dengan menelaah secara holistik suatu produk kebudayaan sebagai suatu lore yang dimiliki oleh masyarakat tertentu dapat memberikan gambaran khusus misalnya terkait filosofi, nilai, mentalitas, kearifan, kebijaksanaan, dan sebagainya.

Dalam hal ini, folk yang ditelaah berkaitan dengan perkembangan kebudayaan masyarakat Banjar sebagai pemilik dari kesenian madibin. Serta selanjutnya menelaah kesenian madibin sebagai produk kebudayaan dari masyarakat Banjar. Dalam tulisan ini penulis mengkaji dengan pendekatan folkore terhadap kesenian Madibin dalam kaitannya dengan pengaruh Islam dalam kebudayaan masyarakat Banjar. Karya tulis ini disusun menggunakan metode pengumpulan data studi literatur atau studi pustaka. Studi pustaka

\footnotetext{
7 Suwardi Endraswara, Metodologi Penelitian Folklor (Yogyakarta: Media Pressindo, 2009).

8 James Danandjaja, Folklore Indonesia: Ilmu Gosip, Dongeng, dan lain-lain (Jakarta: PT. Pustaka Utama Grafiti, 1984).

9 Alan Dundes, The Meaning of Folklore: The Analytical Essays of Alan Dundes (Utah, United States of America: Utah State University Press, 2007).
} 
adalah kajian teoritis, referensi serta literatur ilmiah lainnya yang berkaitan dengan budaya, nilai dan norma yang berkembang pada situasi sosial yang diteliti. ${ }^{10}$

\section{Pembahasan}

Kehadiran Islam di daerah maritime Asia Tenggara dapat dilacak sejak awal masa khalifah ketiga Islam, 'Utsman (644-56), yang mengirim utusan (emissaries) Muslim dari Arab ke Cina. Pada abad ke-9 ada ribuan pedagang Muslim di Canton, China. Kontak antara Cina dan dunia Islam utamanya melalui jalur laut melalui perairan nusantara. ${ }^{11}$

Secara formal Islam telah membentuk lembaga politiknya di Samudera Pasai pada abad ke-7 Hijriah (13 M) dengan rajanya bernama Malik As-Saleh, yang wafat pada bulan Ramadhan 698 Hijriah (1297 M). Pada awal abad ke-16 berdiri Kesultanan Demak (1518-1550 M) dengan rajanya yang pertama Raden Patah. ${ }^{12}$

Sulit untuk menemukan sumber primer tentang kapan dan siapa yang paling awal yang berperan dalam Islamisasi di Banjarmasin, kecuali sumbersumber yang memberikan hipotesa tentang terbentukanya komunitas Muslim di Banjarmasin. Dari kajian pustaka yang dilakukan oleh Yusliani Noor (2012), menunjukkan cukup banyak sumber-sumber referensi yang menjelaskan tentang pengaruh Islam terhadap Banjar. Misalnya, sebuah naskah tua yang terbilang langka karya W.P Groeneveldt, naskah ini diterjemahkan oleh Gatot Triwira dan diterbitkan Komunitas Bambu (2009), kemudian diberi judul Nusantara dalam catatan Tionghoa. Isi naskah ini menggambarkan Banjarmasin dalam Catatan Dinasti Ming (1386-1643), sebuah catatan yang paling diperlukan untuk menggambarkan kondisi Banjarmasin abad ke-14 hingga abad ke-17. ${ }^{13}$

Sumber lain adalah Hikayat Banjar (dan Raja-Raja Kota Waringin). Sumber ini dalam masyarakat Banjar disebut sebagai Hikayat Lambung Mangkurat atau Tutur Candi. Hikayat Banjar ditulis memakai huruf Arab Bahasa Melayu Banjar. Naskah ini ditulis pada 1828, yang dijadikan disertasi

\footnotetext{
10 Sugiyono, Memahami Penelitian Kualitatif (Bandung: Alfabeta, 2012).

${ }^{11}$ Merle Calvin Ricklefs, A History of Modern Indonesia Since 1300 Century (London: The Macmillan Press Ltd, 1994)

12 ibid

13 Yusliani Noor, "Sejarah Perkembangan Islam di Banjarmasin dan Peran Kesultanan Banjar (Abad XIV - XIX)”, dalam al-Banjari, Vol.11 No.2 2012, hlm. 239-263.
} 
oleh Anton Abraham Cence dengan judul "De Kroniek van Banjarmasin" (Kronik Banjarmasin). Disertasi lainnya ditulis oleh Johannes Jacobus Ras, dengan judul "Hikayat Banjar, A Study in Malay Historiography"."

Baik Cence maupun Ras sepakat membagi periodesasi kesejarahan masyarakat Banjar, dari periode kerajaan Hindu-Budha, yakni kerajaan Negara Dipa dan Kerajaan Negara Daha sampai berdirinya Kesultanan Banjarmasin.

Penduduk di selatan Borneo (sebutan lain Kalimantan) pada awalnya mendapat pengaruh kepercayaan Hindu, hal ini dperkuat dengan bukti peninggalan arkeologis, Candi Agung dan Candi Laras, yang ditemukan di daerah Amuntai, Kalimantan Selatan. Pada tahun 1996 dilakukan pengujian C14 terhadap sampel arang Candi Agung yang hasilnya memperkirakan materialnya berasal dari tahun $242-226$ SM. ${ }^{15}$ Islam masuk ke Kalimantan Selatan lebih belakang dibanding daerah lainnya, misalnya, Sumatera bagian utara, Jawa, dan Semenanjung Malaysia.

Melihat dari teori-teori tentang saluran Islamisasi, baik yang dikaji oleh para orientalis, misalnya J.C. Van Leur, B.O. Scherieke, Pijnappel. J.P. Maqquete, C. Snouck Horgronje, Crewfurd, Keyzer, Niemann, dan Hollander, van Brueinessen, hingga Karel Steenbrink. Sedangkan dari kalangan Muslim antara lain; Syed Muhammad Naquib Al-Attas, Fatimi, Buya Hamka, P.A. Hoesein Djajadiningrat, Azyumardi Azra dan Eka Tjandrasasmita, hasil kajian mereka menunjukkan bahwa Islamisasi Nusantara melalui saluran-saluran; perdagangan, perkawinan, birokrasi pemerintahan, ilmu tasawuf dan tarekat, pendidikan serta kesenian. ${ }^{16}$

Diperkirakan telah ada sejumlah muslim di wilayah ini sejak awal abad ke-15, tetapi Islamisasi mencapai momentumnya baru setelah pasukan Kesultanan Demak datang ke Banjarmasin untuk membantu Pangeran Samudra, putera mahkota Kerajaan Daha (sebelum berubah nama menjadi Kerajaan Banjar), dalam konfliknya dengan elit istana di Kerajaan Daha. Setelah memperoleh kemenangan Pangeran Samudra memenuhi janjinya untuk memeluk agama Islam pada sekitar tahun 936 H/1526 Masehi dan diangkat sebagai sultan pertama di Kesultanan Banjar dengan gelar Sultan Suriansyah. ${ }^{17}$

\footnotetext{
${ }^{14}$ Ibid.

15 Ibid.

16 Ibid.

17 Baca: Azyumardi Azra, The Origins of Islamic Reformism in Southeast Asia, (Australia: Allen \& Unwim Publisher, 2004).
} 
Secara sepintas, Islamisasi masyarakat Banjar sepenuhnya hasil dari campur tangan Kesultanan Demak, sehingga pemahaman penyebaran Islam di Banjarmasin diartikan sebagai bentuk ekspansi dan kekerasan. Apalagi buktibukti peninggalan Hindu-Budha, seperti Candi Agung dan Candi Laras, hanya meninggalkan sisa-sisa reruntuhan bangunan, yang hancur seakan-akan akibat penyerbuan pasukan Demak. Padahal, Hikayat Banjar juga menyebutkan, bahwa Kesultanan Demak sendiri mengutus seorang Khatib ke Banjarmasin, yang bernama Khatib Dayyan. Gelar atau nama Khatib Dayyan lebih mencerminkan nama seorang penyampai khotbah atau penyiar agama daripada nama atau seorang panglima perang. Anggapan adanya ekspansi dan kekerasan dalam Islamisasi Banjarmasin, meniadakan peran saluran-saluran Islamisasi Nusantara yang justru lebih penting dan dominan dalam menggambarkan kedatangan, penerimaan dan penyebaran Islam di Banjarmasin. ${ }^{18}$

Menurut Yusliani Noor (2012), saluran-saluran islamisasi inilah yang harus dikaji lebih mendalam sehingga akan terlihat bentuk jaringan-jaringan sosial yang berhasil menyebarkan Islam di Banjarmasin yang mencakup; islamisasi yang dikembangkan melalui perdagangan, perkawinan, birokrasi pemerintahan, tasawuf dan tarekat, pendidikan dan kesenian. Muaranya adalah terbentuknya Urang Banjar (sebutan untuk orang yang beretnis Banjar) dan masyarakat Banjar, yang menjadikan Islam sebagai jati diri dan identitas kolektifnya. ${ }^{19}$

Terkhusus untuk islamisasi melalui jalur kesenian dikembangkan oleh Bubuhan (kekeluargaan/kekerabatan) Tutus, Bubuhan Tuan Guru dan Bubuhan Jaba. Kesenian Wayang Kulit Banjar, Wayang Orang, Wayang Gong, Ba'da Muluk, Mamanda, Madihin, Balamut, Barudat, Japen, dan lain-lain, sebagian besar merupakan pengaruh dari kebudayaan Melayu, kecuali Wayang Kulit Banjar yang berasal dari Jawa, khususnya dari Demak. Kesenian Baayun Maulud, di Mesjid Banua Halat Rantau sebagai peninggalan dari datu Ujung. Sementara tradisi ini di Tambak Anyar, Martapura yang diselingi syair "Huwal Awwal Damai Dandam", syair "Hasan Husen", dan budaya membuat Bubur Asyura setiap tanggal 10 Muharram menunjukkan gejala adanya pengaruh Persia. ${ }^{20}$

\footnotetext{
18 Yusliani Noor, "Sejarah Perkembangan Islam di Banjarmasin dan Peran Kesultanan Banjar (Abad XIV - XIX)", dalam al-Banjari, Vol.11 No.2 2012, hlm. 239-263.

19 Ibid.

${ }^{20}$ Ibid.
} 


\section{Penyajian Kesenian Madihin}

Para pemadibinan (orang yang membawakan madihin) menyampaikan pantun-pantun tanpa mengacu kepada wacana yang ditulis lebih dahulu, apa yang diucapkan muncul secara spontan. Walaupun demikian tema memang harus ditetapkan terlebih dahulu. Kadang-kadang tema itu diberikan beberapa saat sebelum pemadibinan memulai penyajiannya. Dari tema yang diberikan itulah pamadibinan berangkat dan mengembangkan cerita itu dengan ketrampilannya menyusun larik-larik pantun. ${ }^{21}$

Madibin dibawakan dengan irama -dilagukan- dengan diiringi alat musik tarbang. Tarbang secara fisik mirip seperti gendang rebana atau alat musik tabuh lainnya, terbuat dari kayu dengan bingkai dan pengikat dari rotan serta selaput getar atau kulit yang dibuat dari kulit kambing. Bentuknya seperti kerucut terpancung mendatar yang mana bagian mukanya lebih besar atau lebih lebar daripada ujung bagian belakang yang berbingkai dengan rotan untuk mengencangkan kulit muka yang ditabuh tersebut. ${ }^{22}$

Ciri-ciri pantun madihin mirip dengan pantun Melayu. Pantun Melayu memiliki ciri-ciri, yaitu: (a) terdiri atas empat baris, (b) tiap baris terdiri atas 8 sampai 10 suku kata, (c) dua baris pertama disebut sampiran dan dua baris berikutnya mengandung maksud si pemantun yang disebut isi pantun, dan (d) pantun mementingkan rima akhir dan rumus rimanya $a-b-a-b{ }^{23}$

Madibin tidak selalu berpola sama seperti pantun Melayu yang mempunyai pola bunyi persajakan akhir $a-b-a-b$. Pantun madihin dapat saja mempunyai bunyi persajakan akhir sama $a-a-a-a$. Oleh kerana itu, orang sering mengira bahawa pantun madihin sebenarnya adalah syair. ${ }^{24}$

Namun madibin berbeda dengan syair. Syair membawakan cerita atau lakon kerana itu syair mempunyai alur yang tegas serta jelas pula tokoh-tokoh lakonnya. Pantun tidak membawakan lakon seperti syair, kerana itu tokohnya pun tidak ada. Demikian juga halnya dengan pantun madihin yang tidak ada

21 Agus Yulianto, "Madihin: Tradisi Tutur dari Zaman ke Zaman", dalam Jurnal Naditira Widya Vol. 4 No. 2 2010, hlm. 257-263.

22 M. Rafiek, "Pantun Madihin: Kajian Ciri, Struktur Pementasan, Kreativiti Pemadihinan, Pembangunan, dan Pembinaannya di Kalimantan Selatan", dalam Jurnal Pendidikan Babasa Melayu Vol. 2 No. 22002.

${ }^{23}$ Ibid

${ }^{24}$ Hasuna dan Lismayanti, "Madihin sebagai Kesenian Tradisional Masyarakat Banjar" dalam LENTERA: Jurnal Ilmiah dan Kependidikan Vol. 12, No. 1 2017, hlm. 38 -50. 
tokohnya kalaupun ada itu muncul secara spontan dan sama sekali tidak membentuk alur. ${ }^{25}$

Struktur penyampaian pantun madihin terdiri atas 4 langkah, yaitu: ${ }^{26}$

a. Pembukaan, dengan melagukan sampiran sebuah pantun yang bermula pukulan terbang yang disebut pukulan membuka. Sampiran pantun ini biasanya akan memberikan maklumat tema apa yang akan dibawakan dalam penyampaian pantun madihin.

Pembukaan:

Asalammualaikum ulun mangawalinya (Asalammualaikum saya mengawalinya)

Sabagai salam untuk pian samuanya (Sebagai Salam untuk hadirin semuanya)

Bukanlah ulun pamadibinan asalnya (Bukanlah saya pamadihinan asalnya) Mun ulun salah, mubun pian mamakluminya (Kalau saya salah, mohon hadirin memaklumkannya)

Madibin ulun ini, madibin reformasi (Madihin saya ini, madihin reformasi) Amun kada parcaya, silabakan mandangari (Kalau tidak percaya, silakan mendengarkan)

Kini ulun mambawaakan ulahan sandiri (Kini saya membawakan buatan sendiri)

Dengan judul babakti lawan kuitan laki (Dengan judul berbakti dengan orang tua laki)

b. Mamasang tabi, membawakan syair-syair atau pantun yang isi kandungannya menghormati penonton, dan memohon maaf jika terdapat kekeliruan dalam penyampaian.

Mamasang Tabi:

Tarima kasib ulun ucapakan (Terima kasih saya ucapkan)

Atas sambutan sampiyan samuanya (Atas sambutan hadirin semuanya)

Amun ulun salah, jangan ditatawaakan (Kalau saya salah, jangan ditertawakan)

25 M. Rafiek, "Pantun Madihin: Kajian Ciri, Struktur Pementasan, Kreativiti Pemadihinan, Pembangunan, dan Pembinaannya di Kalimantan Selatan", dalam Jurnal Pendidikan Bahasa Melayu Vol. 2 No. 2002.

${ }_{26}$ Mengenai struktur dari penyampaian pantun madibin semua budayawan dan peneliti bersepakat membaginya menjadi: pembukaan, mamasang tabi, menyampaikan isi (manguran), dan penutup. 
Maklumlah ulun hanyar cacobaan (Maklumlah saya baru coba-coba)

Salamat datang hadirin nang tarhormat (Selamat datang hadirin yang terhormat)

Kuncap salam supaya samua salamat (Kuucap salam supaya semua selamat)

Tasanyum dulu itu sabagai syarat (Tersenyum dahulu itu sebagai syarat)

Supaya salamat dunia lawan akbirat (Supaya selamat dunia dan akhirat)

Baik nang sumbing atawa giginya jubing (Baik yang sumbing atau gigi maju ke depan)

Baik nang langkar atawa nang tagantar (Baik yang cantik atau yang gangguan jiwa)

Baik nang bujang atawa baranakan (Baik yang bujang atau punya anak)

Baik nang baingusan atawa baliuran (Baik yang keluar ingus atau keluar liur)

Baik nang takuribing atawa takujibing (Baik yang tersenyum atau tersenyum lebar)

Baik. kulit kancang atawa nang janggut panjang (Baik kulit kencang atau yang janggut panjang)

c. Menyampaikan isi (manguran), yaitu menyampaikan syair-syair atau pantun yang selalu selaras dengan tema penyampaian atau sesuai dengan permintaan pihak penyelenggara. Sebelum sampiran pantun dipembukaan harus disampaikan isi kandungannya terlebih dahulu (mamacah bunga).

Penyampaian (Manguran):

Gamalan piluk di kandang jati (Gamelan piluk di kandang jati)

Minum cuka di kandang bilaran (Minum cuka di kandang bilaran)

Samunyaan makbluk mamandang mati (Semuanya makhluk memandang mati)

Anum tuba mabadang giliran (Muda tua menunggu giliran)

Urang bidup ada di mana-mana (Orang hidup ada di mana-mana)

Urang mati apa kada di sangka (Orang mati apa tak disangka)

d. Penutup, menyampaikan kesimpulan dari apa yang baru saja di sampaikan sambil menghormati penonton, dan mohon pamit, serta ditutup dengan pantun-pantun serta lagu-lagu.

Penutup: 
Di satop dahulu ulun bamadibinan (Di stop dahulu saya bermadihinan) Ngalu kapala bapandir kada karuan (Sakit kepala berbicara tidak keruan) Handak rasanya ulun mangacak pian (Hendak rasanya saya mencengkram hadirin)

Biar badiam pian batatawaan (biar berdiam hadirin tertawaan)

Tarima kasib ulun haturakan (Terima kasih saya haturkan)

Atas parbatian sampai di pabujungan (Atas perhatian sampai di akhiran)

Cukup sakian ulun mamadahakan (Cukup sekian saya menasihatkan)

Agar jangan salab dalam manarapakan (Agar jangan salah dalam menerapkan)

\section{Fungsi Kesenian Madihin}

Tidak sulit mengindentifikasi fungsi kesenian madibin, karena kesenian ini tidak termasuk kesenian yang berlatar belakang sakral. Fungsi utama madibin adalah sebagai hiburan bagi masyarakat pada waktu-waktu tertentu. Namun lebih jauh selain fungsi hiburan, madihin juga memiliki fungsi nasihat agama Islam, kritik dan protes sosial seperti sindiran, media untuk perbaikan moral dan karakter, serta pendidikan. ${ }^{27}$

\section{Pengaruh Islam dan Kebudayaan Mealyu Terhadap Kesenian Madihin Masyarakat Banjar}

Umumnya penduduk nusantara pra-Islam sebenarnya sudah disesaki oleh lantunan syair tradisional yang terendam dalam bentuk mantra-mantra. Ciri yang paling menonjol adalah isinya yang masih animistik, yakni berisi pemujaan atas kayu, laut, sungai, hutan, gunung, hewan dan lain-lain yang dipercaya memberikan kekuatan tertentu. Ketika Islam masuk, tradisi merapal mantra perlahan mendapatkan pengaruh, yakni seperti menyertakan kalimat bismillabirrahmanirrahim atau laa ilaha illallah. ${ }^{28}$

Terciptanya entitas Melayu yang berbasiskan pada heterogenitas manusia lintas benua, menerbitkan babak baru bagi peradaban Nusantara. Seiring dengan didapuknya bahasa Melayu sebagai alat komunikasi Nusantara

27 S. Faridah, "The Functions of Humor in the Madihin Banjar Art", dalam International Journal of Academic Research and Development Vol. 2 2017, Issue. 4, hlm. 576581.

${ }^{28}$ M. Dien Madjid. "Relasi Kebudayaan Arab dan Melayu dalam Sejarah di Indonesia", dalam Jurnal al-Turas Vol. XIX No.2 2013. 
(lingua franca) perlahan turut pula membawa angin segar bagi gairah berbudaya masyarakatnya. Laiknya Hindu dan Budha sebelumnya, ajaran Islam tidak hanya terpaut pada kesadaran kosmik semata, melaikan turut pula mengental dalam realitas sosial, bahkan menjelma menjadi piranti-pirantinya. ${ }^{29}$

Bahasa Melayu-Banjar sebagai bahasa Lingua Franca menjembatani komunikasi antar etnis di Banjarmasin. Selain itu Huruf Arab-Melayu, juga dipakai dalam penulisan kitab-kitab klasik berbahasa Banjar yang dikarang cendekia Banjar, contohnya Kitab Sabilal Mubtadin dan Contoh tulisan berbahasa Banjar yang menggunakan huruf Arab-Melayu adalah Kitab Sabilal Mubtadin dan Tubfaturragibien. ${ }^{30}$

Pengaruh Melayu juga banyak berperan dalam kesenian masyarakat Banjar. Pengaruh tersebut tidak saja menyangkut bahasa tetapi juga pemikiran dan budaya. Lama-kelamaan terjadi perpaduan yang harmonis antara kebudayaan yang pada mulanya masih terpengaruh Hindu dengan kebudayaan Melayu yang bernafaskan Islam. Perpaduan tersebut menciptakan suatu kebudayaan baru di daerah Kalimantan Selatan yaitu budaya Banjar yang merupakan hasil dari pertemuan dua titik kebudayaan tersebut. ${ }^{31}$

Secara kultural kebudayaan Melayu banyak menyerap nilai-nilai ke-Islaman maupun budaya Arab. Misalnya penggunaan huruf klasik Arab-Melayu serta bahasa Melayu yang banyak menyerap kosa kata Arab, terutamanya perkataan-perkataan yang berhubung dengan agama, politik, falsafah, moral dan lain-lain. ${ }^{32}$

Sejak awal abad ke-15, Kalimantan bagian selatan sudah mempunyai kantong-kantong pemukiman yang cukup banyak. Selain daerah sekitar Keraton Bandarmasih yang dihuni etnis Melayu, pemukiman komunitas serupa juga berada di daerah-daerah Tabalong, Kalua, Amuntai, Nagara, Barabai, Kandangan, dan Rantau. Pada saat itu, kawasan budaya Banjar sudah

29 Ibid.

30 Penjelasan Yusliani Noor (2012) berdasarkan kajian pustaka terhadap penjelasan De Clereq (1877) dalam Tijdschrift voor Indisch Taal-Volken kunde. Contoh tulisan berbahasa Banjar yang menggunakan huruf Arab-Melayu adalah Kitab Sabilal Mubtadin dan Tuhfaturragibien.

31 Agus Yulianto, "Madihin: Tradisi Tutur dari Zaman ke Zaman", dalam Jurnal Naditira Widya Vol. 4 No. 2 2010, hlm. 257-263.

32 Abbas Mohd. Shariff, Pengarub Bahasa Arab kepada Bahasa Melayu (Singapura: Malay Language Council, 1988). 
mengenal budaya Islami. Oleh karena itu pula, banyak kesenian Banjar pada saat itu memiliki nafas Islam. ${ }^{33}$

Madihin adalah salah satu bentuk sastra lisan berbahasa Banjar yang lahir, tumbuh, dan berkembang dalam masyarakat Banjar setelah Islam berkembang di Kalimantan. Lahirnya madihin banyak dipengaruhi oleh kesenian Melayu - Islam, yaitu qasidab. ${ }^{34}$

Kemiripan madibin dan kesenian qasida, dapat mengindikasikan adanya pengaruh kebudayaan Melayu-Islam terhadap kesenian madibin. Qasida berasal dari Arab, berbentuk syair-syair pujian masyarakat Badui (Bedonion), kesenian ini telah ada sebelum dimulainya misi kenabian Muhammad SAW. ${ }^{35}$

Qasida bernuansa religius, berkembang baik mulai abad ke-XII. Awalnya qasida hanya berupa pujian-pujian kepada nabi (shalawat). Di masa ini tematema kesufian dan nasehat-nasehat agama menjadi popular. Hal ini berhubungan dengan berkembangnya Sufisme yang mulai dominan dalam syiar publik. Adaptasi pola-pola kesufian juga berpengaruh besar dalam perkembangan kesusasteraan di India, kepulauan nusantara, Swahili dan Housa. Qasida modern berkembang di Indonesia, di mana qasida berubah fungsi menjadi tujuan dakwah, sebagai hasil ekspresi perpaduan budaya Islam dan budaya lokal. ${ }^{36}$

Mudahnya kebudayaan Melayu yang bernafaskan Islam dalam mempengaruhi kebudayaan Banjar tidak lain disebabkan adanya beberapa kemiripan di antara dua kebudayaan tersebut. Karena itu pula, berbagai kegiatan seni budaya dalam masyarakat Banjar seperti bidang sastra, seni suara, musik, tari, dan teater rakyat memiliki lintas budaya dengan konsepsi estetika seni budaya bangsa Melayu seperti rudat, zapin, hadrah, dundam, lamut, mamanda, dan madibin. Kesamaan tersebut menyangkut instrumen yang digunakan, irama, dan bahasa.

\footnotetext{
33 Ibid.

34 M. Rafiek, "Pantun Madihin: Kajian Ciri, Struktur Pementasan, Kreativiti Pemadihinan, Pembangunan, dan Pembinaannya di Kalimantan Selatan", dalam Jurnal Pendidikan Bahasa Melayu Vol. 2 No. 22002.

35 Penjelasan Sir Dennison Ross dalam bukunya "Eastern Art and Literature: Special Reference to China, Arabia, India, and Persia. Dikutip melalui review H.T. Norris, "Qașīda Poetry in Islamic Asia and Africa Vol. 1-2", dalam Bulletin of the School of Oriental and African Studies, University of London, Vol. 60, No. 2 2016, hlm. 353-355.

36 Stefan Sperl dan Christofer Shackle, Qasida Poetry in Islamic Africa and Asia (Leiden: E.J Brill, 1996).
} 


\section{Simpulan}

Budaya masyarakat Banjar merupakan transformasi dan transkulturasi religiusitas kepercayaan pra-Islam dengan paska islamisasi. Pertemuan keduanya menghasilkan suatu entitas Banjar baru yang dipengaruhi kuat oleh nilai dan ajaran Islam serta kebudayaan melayu. Dari sekian contohnya adalah penyerapan bahasa Melayu, serta penggunaan huruf Arab-Melayu sebagai alat komunikasi verbal masyarakat Banjar.

Dalam bidang kesenian, sastra lisan madibin muncul sebagai hasil dari asimilasi antara kebudayaan Melayu-Islam dan Banjar. Madibin memiliki kesamaan dengan sastra lisan melayu sejenis pantun dan syair, namun disampaikan dalam bahasa Banjar, dengan rima yang tidak mesti teratur (misalnya harus: $a-a-a-a$ atau $a-b-a-b)$, jumlah bait yang tidak baku, dan tidak melakonkan suatu drama tertentu.

Kemunculan madibin merupakan transformasi bentuk qasida yang hadir ke Nusantara saat berkembangnya Islam. Penggunaan tarbang sebagai instrumen musik pengiring dalam pertunjukkan madibin, mirip dengan kesenian qasida dengan gendang rebana-nya. Namun madibin berbeda dengan kesenian qasida yang liriknya merupakan bait-bait lagu, madibin merupakan penyampaian sastra lisan sejenis pantun dan syair yang dilagukan, serta tidak terlalu mementingkan kesesuaian bait lirik dengan irama, satu kesesuaian yang penting dalam musik qasida.

\section{Daftar Pustaka}

Azra, Azyumardi. The Origins of Islamic Reformism in Southeast Asia. Australia: Allen \& Unwim Publisher, 2004.

Danandjaja, James. Folklore Indonesia: Ilmu Gosip, Dongeng, dan lain-lain. Jakarta: PT. Pustaka Utama Grafiti, 1984.

Dundes, Alan. The Meaning of Folklore: The Analytical Essays of Alan Dundes. Utah, United States of America: Utah State University Press, 2007.

Endraswara, Suwardi. Metodologi Penelitian Folklor. Yogyakarta: Media Pressindo, 2009.

Faridah, S. "The Functions of Humor in the Madihin Banjar Art", International Journal of Academic Research and Development Vol. 2 2017, Issue. 4, hlm. 576-581.

Hasuna dan Lismayanti, "Madihin sebagai Kesenian Tradisional Masyarakat Banjar”, LENTERA: Jurnal Ilmiah dan Kependidikan Vol. 12, No. 12017 , hlm. $38-50$. 
Madjid. M. Dien. "Relasi Kebudayaan Arab dan Melayu dalam Sejarah di Indonesia", Jurnal al-Turas Vol. XIX No.2 2013.

Noor, Yusliani. "Sejarah Perkembangan Islam di Banjarmasin dan Peran Kesultanan Banjar (Abad XIV - XIX)", al-Banjari, Vol.11 No.2 2012, hlm. 239-263.

Norris, H.T. "Qașīda Poetry in Islamic Asia and Africa Vol. 1- 2", Bulletin of the School of Oriental and African Studies, University of London, Vol. 60, No. 2 2016, hlm. 353-355.

Rafiek, M. "Pantun Madihin: Kajian Ciri, Struktur Pementasan, Kreativiti Pemadihinan, Pembangunan, dan Pembinaannya di Kalimantan Selatan", Jurnal Pendidikan Bahasa Melayu Vol. 2 No. 2002.

Ricklefs, Merle Calvin. A History of Modern Indonesia Since 1300 Century. London: The Macmillan Press Ltd, 1994.

Shariff, Abbas Mohd. Pengarub Bahasa Arab kepada Babasa Melayu. Singapura: Malay Language Council, 1988.

Sperl, Stefan dan Christofer Shackle. Qasida Poetry in Islamic Africa and Asia. Leiden: E.J Brill, 1996.

Sugiyono, Memahami Penelitian Kualitatif. Bandung: Alfabeta, 2012.

Suryana. Buku Ajar Perkuliaban: Metode Penelitian Kualitatif dan Kuantitatif. Bandung: Universitas Pendidikan Indonesia, 2010.

Syukrani, M. Deskripsi Madibin. Jakarta: Departemen Pendidikan dan Kebudayaan, 1995.

Yulianto, Agus. "Madihin: Tradisi Tutur dari Zaman ke Zaman”, Jurnal Naditira Widya Vol. 4 No. 22010. 